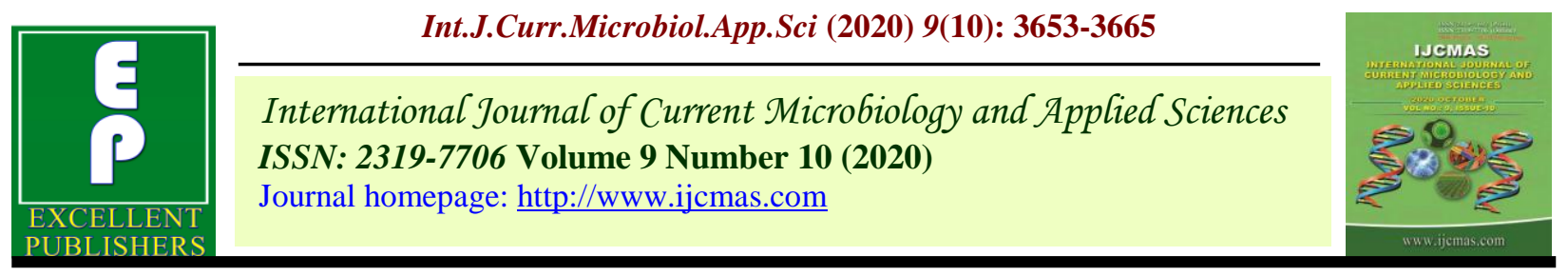

Original Research Article

https://doi.org/10.20546/ijcmas.2020.910.423

\title{
Assessment of Antioxidant and Quantitative Estimation of Momordica charantia (Leaves and Fruit) Plant of Cucurbitaceae Family
}

\author{
Ruchika Sharma*, Namrata Dwivedi and Indra Prasad Tripathi
}

Mahatma Gandhi Chitrakoot Gramodaya Vishvavidyalaya, Chitrakoot, Satna, (M.P), India

*Corresponding author

\section{A B S T R A C T}

\section{Keywords}

Momordica charantia, Diabetes, Bitter melon,

Medicinal plant, free radicals, antioxidants, DPPH, ABTS

Article Info

Accepted:

26 September 2020

Available Online:

10 October 2020
Diabetes mellitus is among the most common disorder in developed and developing countries, and the disease is increasing rapidly in most parts of the world. It has been estimated that up to one-third of patients with diabetes mellitus use some form of complementary and alternative medicine. One plant that has received the most attention for its anti-diabetic properties is bitter melon, Momordica charantia (M. charantia), commonly referred to as bitter gourd, kaela and balsam pear. Its fruit is also used for the treatment of diabetes and related conditions amongst the indigenous populations of Asia, South America, India and East Africa. This paper reveals the free radical scavenging activities of available parts (leaves and fruit) of Kaela plants found in the Chitrakoot region of Madhya Pradesh, India. The free radical scavenging studies were conducted by using DPPH and ABTS methods with ascorbic acid standard. It is important to note that further in vivo studies are required to confirm the obtained results. Present work can only reveal the free radical scavenging properties of selected herbs, but their use as drugs depends on the involvement of pharmaceutical companies.

\section{Introduction}

Diabetes mellitus is considered as one of the five leading causes of death in the world. Diabetes mellitus is a major global health concerning with a projected rise in prevalence from 171 million in 2000 to 366 million in 2030. It is a syndrome of disordered metabolism, usually due to a combination of hereditary and environmental causes, resulting in abnormally high blood sugar level (hyperglycemia) ${ }^{1}$. Plant-produced chemical compounds or phytochemicals like alkaloids, glycosides, flavonoids, volatile oils, tannins, resins have been used in a wide range of commercial and industrial applications such as flavors, aromas and fragrances, enzymes, preservatives, cosmetics, bio based fuels and plastics, natural pigments and bioactive compounds ${ }^{2}$. In the field of nutrition, plants and their products have significant importance not only for providing basic nutrients but also for prevention of various maladies. They indeed improve the quality of life throughout the globe. Plant-based traditional medicines are also in use since immemorial times, however, their standardizations is essential in order to assess their potential. 
Epidemiological data portrayed inverse correlation between their consumption and declining incidence of several ailments. Fruits and vegetables contain array of compounds broadly categorized as phytochemicals that have profound influence especially for disease prevention $^{5}$. Momordica charantia contains an collection of biologically active plant chemicals including triterpens, proteins, steroids, alkaloids, saponins, flavonoids and acids due to which plant possesses antifungal, anti-bacterial, anti-parasitic, anti-viral, anti-fertility, anti-tumorous, hypoglycemic and anti-carcinogenic properties. Fruits are used as traditional medication to cure various diseases like: rheumatism, gout, worms, colic, illness of liver and spleen. It is also found useful in the treatment of cancer and diabetes. $^{4}$ The fruit and leaves contain alkaloids, glycoside, saponin like substances, rennin an aromatic volatile oil mucilage. Bitter gourd shows a significant antimicrobial activity and is of great use in medicine for treatment of many diseases such as piles, leprosy, jaundice; diabetes and snake bite. Its fruits and leaves have been shown to exhibit various biological activities including antidiabetic, anti-rheumatic, anti-ulcer, antiinflammatory and anti-tumor ${ }^{5}$.

The Bitter Melon or bitter ground fruit (Bf), normally known as Karella, (family: Cucurbitaceae), is developed in hot countries in South Asia, South America and Africa. The juice of karalla fruit has been proved for hypoglycemic effects in finding type1 diabetes and in type- 2 being diabetes ${ }^{6}$. It is a climbing permanent so as to commonly rise up to $5 \mathrm{~m}$, and bears stretched out fruits by a knobby flore. It is a priceless medicinal and vegetable plant for human fitness and single of the mainly hopeful plants for diabetes. Bitter melon is prevailing nutrient-dense plants unruffled of a complex arrangement of helpful compounds. These contain vitamins, bioactive chemicals, minerals and antioxidants. The fruit control high amounts of Vitamin ${ }^{7}$.

The aim of the present study is to explore more about the free radical scavenging activity of medicinal plants which are based on non-toxic and advantageous secondary metabolites. For the very first time, this plant found particularly in and around Chitrakoot region (Madhya Pradesh, India) was inspected for their free radical scavenging activity by DPPH and ABTS methods. The significance of the present work is that it gives a clue about the radical scavenging properties of the selected plants, which are easily available and widely used by local people.

\section{Experimental}

\section{Chemicals}

Methanol (HPLC grade), water (HPLC grade), ascorbic acid, tris $\mathrm{HCl}, 2,2$ ' - azinobis(3- ethylbenzthiazoline -6-sulphonic acid), ammonium persulfate, were purchased from SRL while 2,2- Diphynyl 1- picrylhydrazyl radical (DPPH), was purchased from Alpha acer.

\section{Collection and identification of plants}

The plant of $M$. charantia were collected from the local area of Chitrakoot Satna (M.P.) and identified. Plant part (leaves and fruit) were collected, washed with fresh water and dried under shade at room temperature separately. The leaves and fruit were grinded coarsely and then powdered, filtered through sieve (30No.) stored in sterile and air tight container for further use. Identification and authentication of the plants (by preparing a herbarium file) was done in Deendayal Research Institute, Chitrakoot. A voucher specimen (AD/A5/H-138) was deposited at the same institute for further references. 


\section{Processing and extract preparation}

After collecting the plants, their different parts were separated and washed in running tap water then with $70 \%$ methanol to remove dust particles, impurities and to prevent microbial infections. These were shade dried at room temperature and crushed to fine powder by using a grinder. Powdered material was kept in air tight containers. The powdered samples were subjected to extraction with $80 \%$ methanol by maceration method using a rotatory shaker. Maceration method was adapted from Tiwari et al., ${ }^{8}$. The extracts were filtered through filter paper (Whatman No.1). The filtrates were evaporated in hot air oven at $60 \mathrm{o}$ C. After sufficient drying, the material is collected in eppendorf tubes for further use. Experiments were performed in triplicates and results were expressed as (mean $\pm \mathrm{SD}$ ). For statistical analysis, software ANNOVA was used.

\section{Determination of total polyphenolic content}

Basic principle of Folin's-Ciocaiteu reagent method: Folin- ciocaiteu, a combination of phosphomolybdic acid and phosphotungstic, is combining to molybdane (Mo8O23) and lungstene (W8O23) for the period of phenol oxidation. This result occurs in alkaline situation provided by sodium carbonate; strength of colour of blue reflects the capacity of phenolic compounds which can be calculated by spectrophotometer.

Total polyphenolic content of leaves extracts was measured by using Folin-Ciocalteu reagent. The $50 \mu \mathrm{l}$ of plant extract diluted with $50 \mu$ water followed by addition of 150 $\mu \mathrm{l}$ of Folin-Ciocalteu reagent (1N) \& $25 \mu \mathrm{l}$ of $\mathrm{Na} 2 \mathrm{CO} 3(20 \% \mathrm{w} / \mathrm{v})$ and incubated at $45 \mathrm{oC}$ for $60 \mathrm{~min}$ then absorbance was measured spectrophotometrically at $765 \mathrm{~nm}$ (BioTekSynergy H4 multimode micro plate reader, BioTek instrument, Inc Winoosci, VT, USA). Absorbance was recorded triplicates. Quantification was performed with respect to the standard curve of Catechol $(\mathrm{y}=$ $0.004 x+0.083, \quad R 2=0.971)$. Results were expressed as milligram of Catechol equivalent per ml of extract ${ }^{9}$.

\section{Determination of flavonoid contents}

Basic principle of aluminium chloride method: The theory of aluminium chloride colorimetric process is aluminium chloride forms acid even complexes by the $\mathrm{C} 4$ keto collection and both C3 and C5 hydroxyl group of flavones and flavonols. In calculation it also forms acid complexes with ortho- dihydroxyl groups in the $\alpha$ or $\beta$ - ring of flavonoids. Standard quercetin solutions of different concentrations for apply to put up the calibration curve.

Total flavonoid in the plant extracts, in brief, $50 \mu \mathrm{l}$ of sample, followed by $50 \mu \mathrm{l}$ of $\mathrm{AlCl}_{3} \cdot 6 \mathrm{H}_{2} \mathrm{O}$ in ethanol and $25 \mu \mathrm{l}$ Sodium acetate, solution added. The absorbance at 430nm was taken (BioTeksynergyH4 multimode microplate reader, BioTek Instruments, Inc Winooski, VT, USA), after $2.5 \mathrm{~h}$ of incubation at $200 \mathrm{C}$. Total flavonoid contents were calculated with respect to the standard curve of the flavonoid quercetin dehydrate $(\mathrm{Y}=0.007 \mathrm{x}+0.104, \mathrm{R} 2=0.998)$. Results were expressed as micrograms of quercetin dehydrate equivalents (QE) per $\mathrm{ml}$ of the extract.

\section{Determination of Flavonol contents}

Flavonol content in the sample (100 times diluted with methanol) was measured by mixing equal volume of plant extract with $2 \%$ $\mathrm{AlCl} 3.6 \mathrm{H} 2 \mathrm{O}$ in a 96 well plate. Absorbance was recorded at 420 nm spectrophotometrically (BioTek synergyH4 multi-mode microplate reader, BioTek 
Instruments, Inc Winooski, VT, USA). Flavonol contents in the extracts were determined with respect to the standard curve of the flavonoid quercetin $(\mathrm{Y}=0.007 \mathrm{x}+0.104$, $\mathrm{R} 2=0.998)$. Results were expressed as micrograms of quercetin equivalents (QE) per $\mathrm{ml}$ of the extract.

\section{DPPH free radical scavenging assay}

Basic principle of DPPH assay: The DPPH antioxidant assay is based on the capacity of 1,1-diphenyl-2-picryl-hydrazyl (DPPH), a stable free radical, to decolorize in the presence of antioxidants. The DPPH radical contains an odd electron, which is responsible for the absorbance at $517 \mathrm{~nm}$ and also for a visible deep purple colour. When DPPH accepts electron and donated antioxidant complex, decolorized the DPPH (from dark violet to light yellow), when we calculated from the changes in absorbance.

The free radical DPPH assay was prepared by 2, 2-diphenyl-1-picrylhydrazyl (DPPH) process. In brief, a 96-well microplate, $50 \mu 1$ of various dilutions $(10-100 \mu \mathrm{g} / \mathrm{ml})$ of methanolic extract $125 \mu \mathrm{l}$ of tris- $\mathrm{HCl}$ buffer (0.1M, pH 7.4) and $125 \mu \mathrm{l}$ of DPPH solution $(0.004 \% \mathrm{w} / \mathrm{v}$ in methanol) were added.

The reaction mixture was shaken well. The DPPH decolourization was recorded at 518 $\mathrm{nm}$ on a BioTekSynergy H4 hybrid multimode micro plate reader (BioTek instruments, Inc Winoosci, VT, USA.), after 30 min incubation in dark.

The percentage of DPPH scavenging by plant extracts obtained in terms of ascorbic acid equivalent concentration. Quantification was performed with respect to the standard curve of Ascorbic acid $\left(\mathrm{y}=0.868 \mathrm{x}+10.40, \mathrm{R}^{2}=\right.$ 0.981). Results were expressed as milligram of Ascorbic acid equivalent per ml of extract. Experiment was done in triplicates. DPPH radical's concentration was calculated using the following equation:

DPPH radical scavenging activity $(\%)=$ $\frac{\left(A_{0}-A_{1}\right)}{A_{0}} \times 100$

Where Ao was the absorbance of the control and A1 was the absorbance in the presence of the sample ${ }^{10}$.

\section{ABTS free radical scavenging assay}

Basic principle of ABTS assay: Method of ABTS was adopted from Asokan et al4, this assay is based on the ability of different substances to scavenge 2-2' azinobis (ethylbenzthiazoline-6- sulfonic acid) or ABTS + radical cation. In its radical type, ABTS has a feature absorbance at $734 \mathrm{~nm}$ which disappears after its lessening by an antiradical complex. Lessening of blue-green ABTS radical colored solution by hydrogen donating antioxidant is calculated by the repression of its characteristic long wave (734nm) absorption spectrum.

The capacity to test samples to scavenge ABTS+ radical cation was compared to ascorbic acid standard. The ABTS+ radical cation was regenerated by mixing $7 \mathrm{Mm}$ stock solution with $2.45 \mathrm{Mm}$ potassium persulphate and incubating for 18 hours in dark at room temperature until reaction was complete and absorbance of ABTS+ cation solution was $0.637( \pm 0.02)$ by diluting water at room temperature then $20 \mu \mathrm{l}$ of test sample with different concentrations were mixed with $180 \mu 1$ of ABTS solution and absorbance was measured at $734 \mathrm{~nm}$ after 5 minutes. Quantification was performed with respect to the standard curve of ascorbic acid ( $\mathrm{Y}=$ $0.264 x+34.56, \quad R 2=0.981)$. The ABTS scavenging capacity of the test samples was compared with ascorbic acid and percentage inhibition calculated as: 
ABTS radical scavenging activity (\%) = $\frac{\left(A_{0}-A_{1}\right)}{A_{0}} \times 100$

Where $\mathrm{A}_{0}=$ Absorbance of control $\mathrm{A}_{1}=$ Absorbance of sample

All the determinations were performed in triplicates $(n=3)$.

\section{Alpha glucosidase inhibition activity}

Basic principle of alpha glucosidase inhibition: Alpha glucosidase inhibitors were work as opposite inhibitors of enzyme required to process carbohydrates, particularly alpha glucosidase enzyme of small intestine in brush border. Inhibition of these enzyme systems reduces the time of carbohydrate absorption. The effect of less glucose is stimulated since the carbohydrates are not break into glucose molecules. $\alpha$-glucosidase inhibitory activity was performed following the method of Tripathi et al., ${ }^{5}$ In brief, Ratintestinal acetone powder was dissolved in 4 $\mathrm{ml}$ of $50 \mathrm{mM}$ ice cold phosphate buffer and sonicated for 6 minutes at $4^{\circ} \mathrm{C}$. After vortexing for 20 minutes, the suspension was centrifuged $\left(10,000 \mathrm{rpm}, 4^{\circ} \mathrm{C}, 30\right.$ minutes $)$ and the resulting supernatant was used for the assay. A reaction mixture containing $50 \mu \mathrm{l}$ of phosphate buffer $(50 \mathrm{mM}$; pH 6.8), $20 \mu \mathrm{l}$ of rat $\alpha$-glucosidase $(1 \mathrm{U} / \mathrm{ml})$ and $25 \mu l$ of sample of varying concentrations was preincubated for $5 \mathrm{~min}$ at $37^{\circ} \mathrm{C}$, and then $25 \mu \mathrm{l}$ of $3 \mathrm{mM}$ PNPG was added to the mixture as a substrate. After incubation at $37^{\circ} \mathrm{C}$ for 30 min, enzymatic activity was quantified by measuring the absorbance at $405 \mathrm{~nm}$ in a micro titer plate reader (Bio-TEK, USA). Acarbose was used as a positive control and water as negative control. Experiments were done in triplicates. IC50 value was quantified using formula ( $\mathrm{y}=0.199 \mathrm{x}+19.19, \mathrm{R} 2=0.958)$. The percentage of enzyme inhibition by the sample was calculated by the following formula:
$\%$ Inhibition $=\frac{\left(A_{\mathrm{o}}-A_{1}\right)}{A_{\mathrm{o}}} \times 100$

Where $\mathrm{A}_{0}=$ Absorbance of control

$\mathrm{A}_{1}=$ Absorbance of sample

The concentration of an inhibitor required to inhibit 50\% of enzyme activity under the mentioned assay conditions is defined as the $\mathrm{IC}_{50}$ value $^{11}$.

\section{Results and Discussion}

The result of present work is shown table-1 and graph-1 show results of polyphenolic contents. A result of flavonoid contents is shown table-2 and graph-2. Results of flavonol contents were given in table- 3 and graph-3. Table-5 and graph-5 show results of DPPH activity and results of ABTS activity are presented in table- 6 and graph- 6 . Table-7 and graph-7 show the results of alpha glucosidase inhibition activity.

\section{Total polyphenolic content}

Plant polyphenols have an exclusive capacity form intermolecular complexes by each other and by large and small molecules ${ }^{\mathbf{1 2}}$. Advantageous properties of these phenolic compounds include antimicrobial, antiviral, anti ulcerogenic, cytotoxic, antihypertensive, hypolipidemies, and anti inflammatory properties $^{13}$.

In the current study, TPC of plants were estimated using folin-ciocalteu method and catechol as standard. Graph-1 shows standard curve of catechol, which is used the quantification of TPC equivalent to catechol $\mu \mathrm{g} / \mathrm{ml}$ in methanol extracts of selected plant samples. Table-1 represents concentration of TPC in catechol equivalent $\mu \mathrm{g} / \mathrm{ml}$. In our study estimated the highest value of total phenolic content was found in M. charantia leaves $(90.25 \pm 0.002)$ following by fruit extract $(24 \pm 0.003) \mu \mathrm{g} / \mathrm{ml}$ respectively. 
Table.1 Concentration of polyphenolic contents and concentration in total flavonoid contents

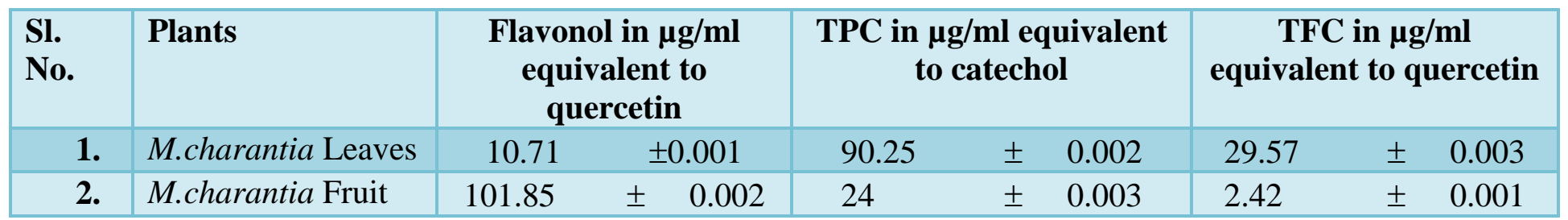

Table.2 $\mathrm{IC}_{50}$ values of samples in $\mu \mathrm{g} / \mathrm{ml}$ equivalent to ascorbic acid in DPPH assay

\begin{tabular}{|c|c|c|c|c|c|}
\hline $\begin{array}{l}\text { Sl. } \\
\text { No. }\end{array}$ & Plants & Parts & \multicolumn{2}{|c|}{$\begin{array}{l}\text { Percentage inhibition } \\
\text { at different cons. }\end{array}$} & $\mathrm{IC}_{50}(\mu \mathrm{g} / \mathrm{ml})$ \\
\hline \multirow[t]{5}{*}{1.} & \multirow[t]{5}{*}{ M.charantia } & \multirow[t]{5}{*}{ Leaves } & 10 & 8.54 & \multirow{5}{*}{$47.96 \pm 0.001$} \\
\hline & & & 20 & 9.11 & \\
\hline & & & 40 & 12.53 & \\
\hline & & & 60 & 14.81 & \\
\hline & & & 80 & 16.80 & \\
\hline \multirow[t]{5}{*}{2.} & \multirow[t]{5}{*}{ M.charantia } & \multirow[t]{5}{*}{ Fruit } & 10 & 23.36 & \multirow[t]{5}{*}{$17.24 \pm 0.001$} \\
\hline & & & 20 & 35.26 & \\
\hline & & & 40 & 42.87 & \\
\hline & & & 60 & 57.65 & \\
\hline & & & 80 & 74.07 & \\
\hline \multirow[t]{5}{*}{3.} & \multirow[t]{5}{*}{ Ascorbic acid } & & 10 & 48.93 & \multirow[t]{5}{*}{$34.59 \mu \mathrm{g} / \mathrm{ml}$} \\
\hline & & & 20 & 49.54 & \\
\hline & & & 40 & 50.30 & \\
\hline & & & 60 & 51.06 & \\
\hline & & & 80 & 51.97 & \\
\hline
\end{tabular}

Table.3 $\mathrm{IC}_{50}$ values of samples in $\mu \mathrm{g} / \mathrm{ml}$ equivalent to ascorbic acid in ABTS assay

\begin{tabular}{|c|c|c|c|c|c|}
\hline $\begin{array}{l}\text { Sl. } \\
\text { No. }\end{array}$ & Plants & Parts & \multicolumn{2}{|c|}{$\begin{array}{l}\text { Percentage inhibition } \\
\text { at different cons. }\end{array}$} & $\mathrm{IC}_{50}(\mu \mathrm{g} / \mathrm{ml})$ \\
\hline \multirow[t]{5}{*}{1.} & \multirow[t]{5}{*}{ M.charantia } & \multirow[t]{5}{*}{ Leaves } & 10 & 10.08 & \multirow[t]{5}{*}{$41.90 \pm 0.001$} \\
\hline & & & 20 & 12.18 & \\
\hline & & & 40 & 15.36 & \\
\hline & & & 60 & 17.11 & \\
\hline & & & 80 & 21.45 & \\
\hline \multirow[t]{5}{*}{2.} & \multirow[t]{5}{*}{ M.charantia } & \multirow[t]{5}{*}{ Fruits } & 10 & 24.63 & \multirow[t]{5}{*}{$28.14 \pm 0.002$} \\
\hline & & & 20 & 36.62 & \\
\hline & & & 40 & 44.78 & \\
\hline & & & 60 & 56.65 & \\
\hline & & & 80 & 64.07 & \\
\hline \multirow[t]{5}{*}{3.} & \multirow[t]{5}{*}{ Ascorbic acid } & & 10 & 37.01 & \multirow[t]{5}{*}{$59.54 \mu \mathrm{g} / \mathrm{ml}$} \\
\hline & & & 20 & 38.94 & \\
\hline & & & 40 & 46.51 & \\
\hline & & & 60 & 50.23 & \\
\hline & & & 80 & 54.74 & \\
\hline
\end{tabular}


Table.4 $\mathrm{IC}_{50}$ values of samples in $\mu \mathrm{g} / \mathrm{ml}$ equivalent to acarbose in Alpha glucosidase assay

\begin{tabular}{|c|c|c|c|c|c|}
\hline $\begin{array}{l}\text { Sl. } \\
\text { No. }\end{array}$ & Plants & Parts & \multicolumn{2}{|c|}{$\begin{array}{l}\text { Percentage inhibition } \\
\text { at different cons. }\end{array}$} & $\mathrm{IC}_{50}(\mu \mathrm{g} / \mathrm{ml})$ \\
\hline \multirow[t]{5}{*}{1.} & \multirow[t]{5}{*}{ M.charantia } & \multirow[t]{5}{*}{ Leaves } & 10 & 0.00 & \multirow[t]{5}{*}{$0.00 \pm 0.00$} \\
\hline & & & 20 & 0.00 & \\
\hline & & & 40 & 0.00 & \\
\hline & & & 60 & 0.00 & \\
\hline & & & 80 & 0.00 & \\
\hline \multirow[t]{5}{*}{2.} & \multirow[t]{5}{*}{ M.charantia } & \multirow[t]{5}{*}{ Fruits } & 10 & 9.86 & \multirow[t]{5}{*}{$409.23 \pm 0.006$} \\
\hline & & & 20 & 10.47 & \\
\hline & & & 40 & 12.24 & \\
\hline & & & 60 & 15.77 & \\
\hline & & & 80 & 16.29 & \\
\hline 3. & L.siceraria & Leaves & 10 & 0.00 & $0.00 \pm 0.00$ \\
\hline \multirow[t]{5}{*}{4.} & \multirow[t]{5}{*}{ Acorbose } & & 10 & 20.21 & \multirow[t]{5}{*}{154.82} \\
\hline & & & 20 & 24.29 & \\
\hline & & & 40 & 28.02 & \\
\hline & & & 60 & 29.62 & \\
\hline & & & 80 & 35.77 & \\
\hline
\end{tabular}

Graph.1 Standard curve of catech Graph-2 and 3: Standard curve of quercetin and Graph-Standard curve of quercetin
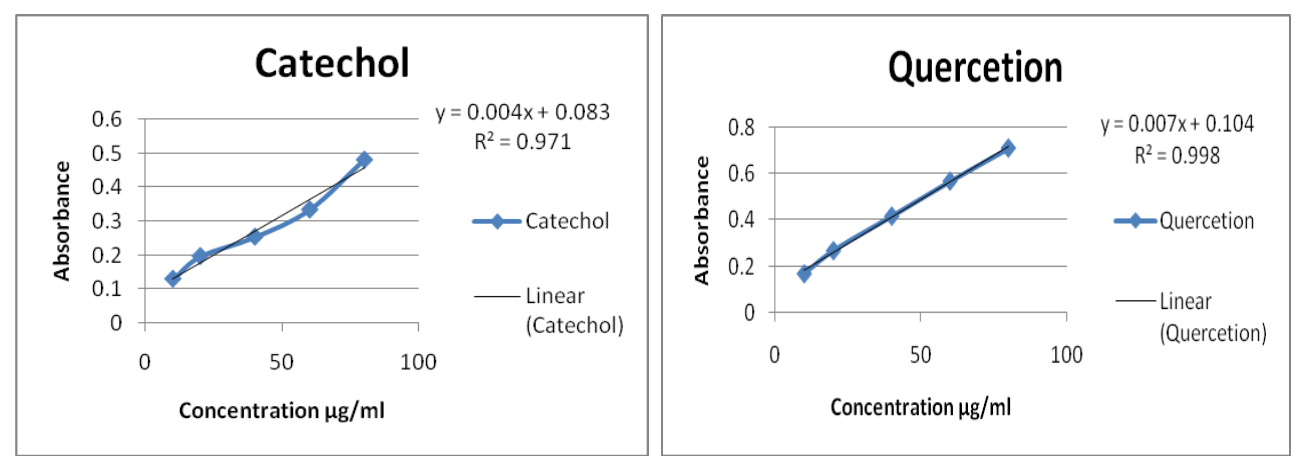

Graph.4 Standard curve of ascorbic acid (DPPH assay and)

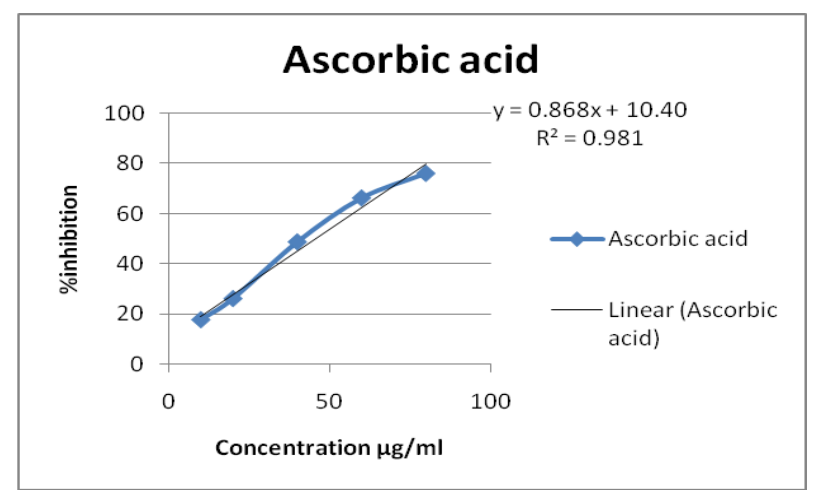


Graph.5 \% inhibition curve of M.charantia plant (DPPH)

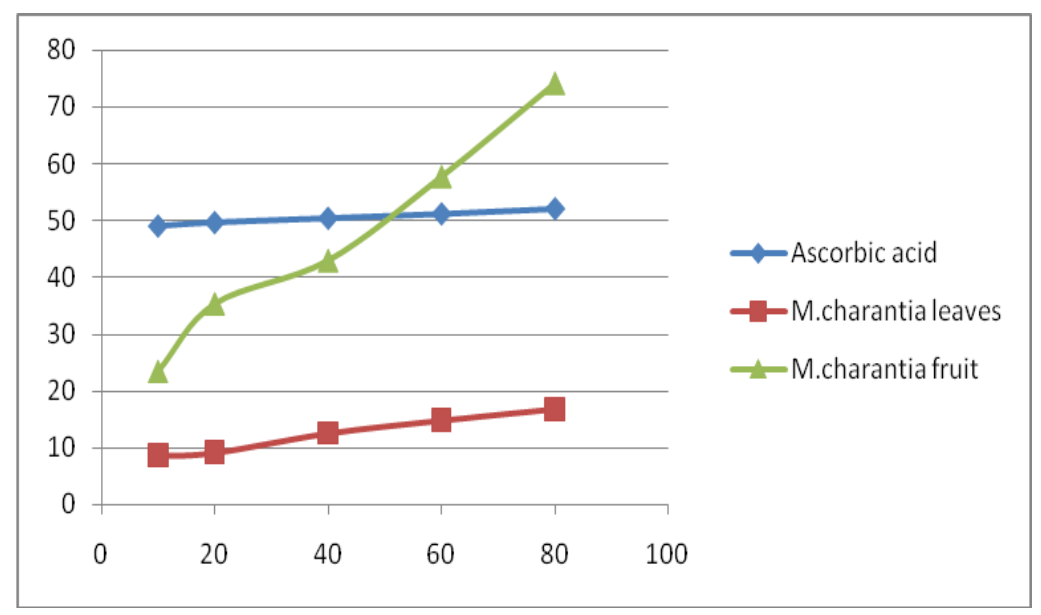

Graph.6 Standard curve of ascorbic acid (ABTS Scavenging assay)

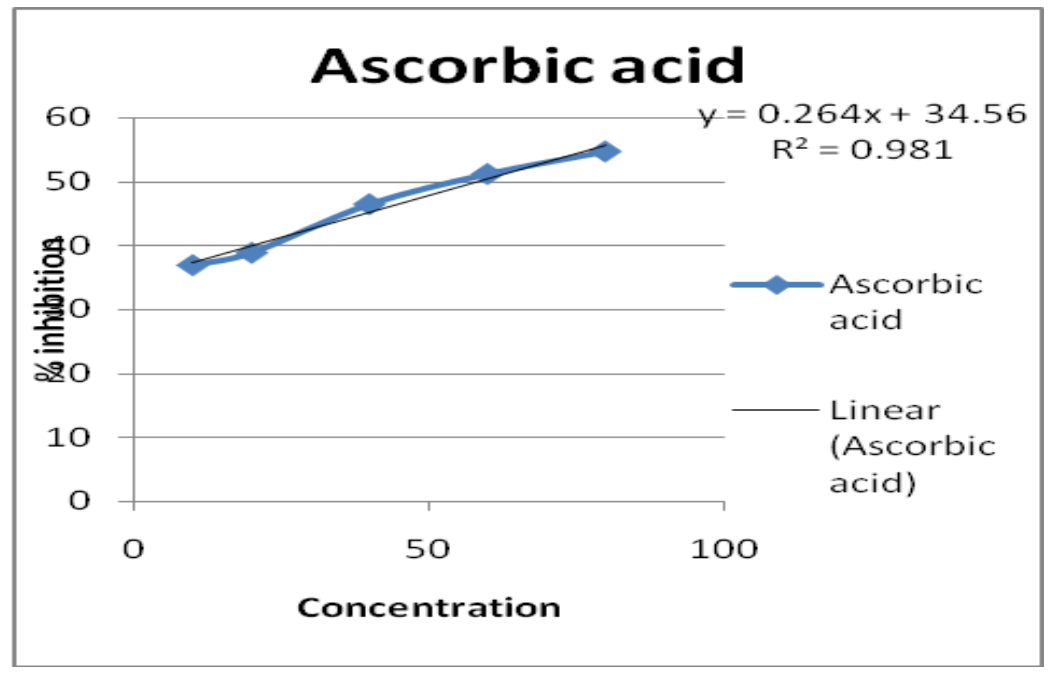

Graph.7 \% inhibition curve of M.charantia plant (ABTS)

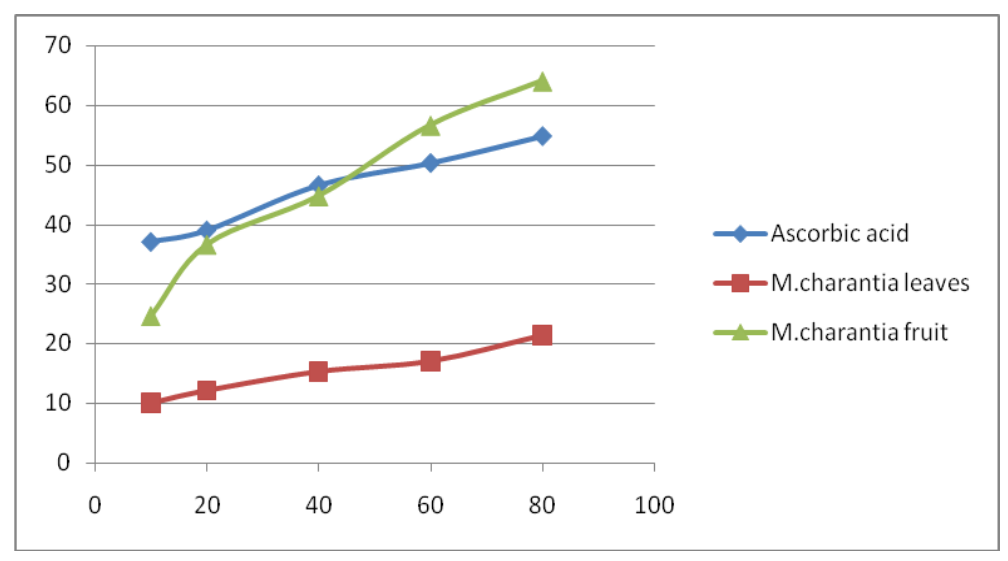


Graph.8: Standard curve of acarbose ( $\alpha$-glucosidase inhibition assay)

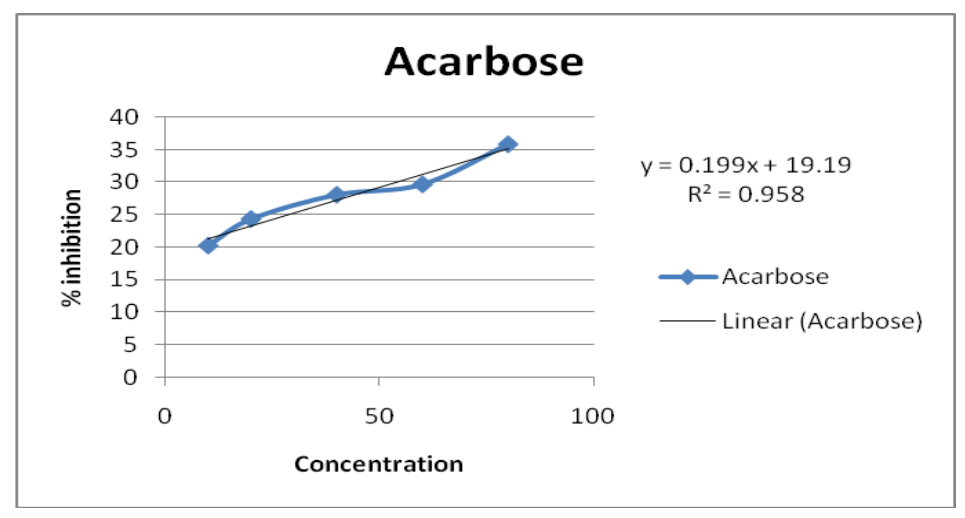

Graph.9 \% inhibition curve of $M$. charantia plant ( $\alpha$-glucosidase inhibition assay)

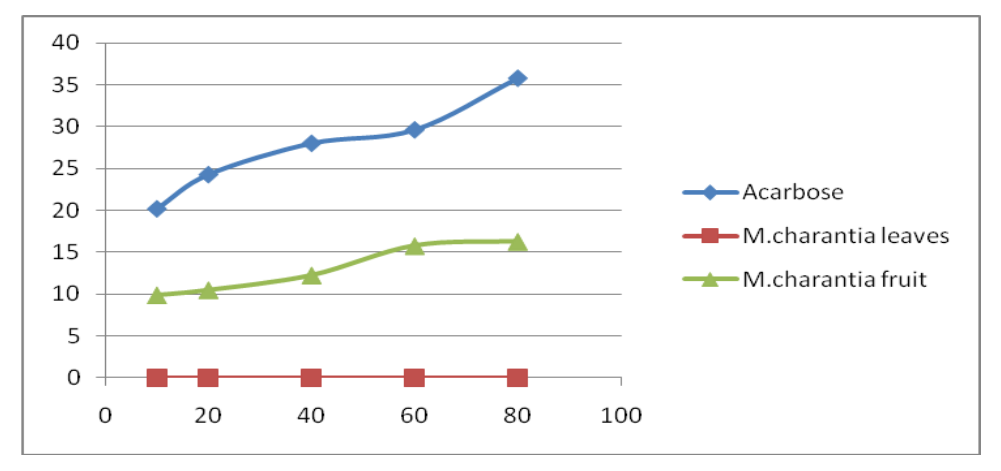

Horax et al. ${ }^{14}$ calculated the phenolic contents in 4 varieties of bitter melon and the ranged from India green (6.52), India white (7.06), China green (5.39) and China white (7.75). Tan et al. ${ }^{15}$, estimated the phenolic compounds in bitter melon and compare water with several organic solvent and found to aqueous extract $63 \%$ and $20 \%$ lower, respectively.

\section{Total flavonoid content}

Flavonoid contents were evaluated using aluminium chloride method and Qurecitin as standard. Graph-2 represents curve of qurecitin, for quantification of flavonoid content, equivalent to Qurcetin $\mu \mathrm{g} / \mathrm{ml}$ in methanolic extract of selected plant samples. Table-1 shows concentration of flavonoid in selected plant sample as a Qurecitin $\mu \mathrm{g} / \mathrm{ml}$. Chahar et al., ${ }^{16}$ studied flavonoid in
M.charania leaves with two extract (petroleum ether and hydro-alcoholic). Hydro-alcoholic was found richest flavonoid (12.16 mg QE/g) and petroleum ether extract was (1.16mg QE/g).

Lee et al., ${ }^{17}$ investigation the flavonoid content of bitter melon at different maturation stages. Flavonoid contents were increase to 639.4 and $203.3 \mathrm{mg} / 100 \mathrm{~g}$ after 35 days.

Patel et al., ${ }^{18}$ studied the flavonoid content of Momoradica charantia Linn. fruit with alcoholic extract and found to be $1.77 \pm$ $0.72 \% \mathrm{w} / \mathrm{w}$ expressed as equivalent to Rutin.

\section{Total flavonols contents}

Flavonols are a major subclass of flavonoids. Quercetin is most commonly found dietary flavonols. Quercetin is reported to decrease 
the risk of intensive cancer in animal models ${ }^{19}$. Flavonols are different chemical composition and characteristics. Beverages vegetables and fruits for example tea and wine is main sources of flavonols ${ }^{20}$. Total flavonoid content of the selected plant was given in table-1, which is similar to earlir report on TFC of selected plants because it is sub class of flavonoid. All results are comparing with Quercetin as standered. Graph-3 shows the standard curve of quercetin

\section{DPPH scavenging activity}

Results of DPPH activity are given table 2 and statistical results of the data are shown in graph 4. Graph 5 shows the curve of standered ascorbic acid. This analysis is based to ability of stable 1, 1'- diphenyl 2- picryl hydrazyl (DPPH) to decolorize the presence antioxidants. DPPH contains electron to responsible for absorbance in 515-517 $\mathrm{nm}$ and come a deep purple colour ${ }^{21}$.

In our work, $\mathrm{IC}_{50}$ value of ascorbic acid in DPPH assay was found to $34.59 \mu \mathrm{g} / \mathrm{ml}$. Outcomes of our research M.charinta fruit (17.24) $\mu \mathrm{g} / \mathrm{ml}$ exhibited excellent antioxidant the terms of $\mathrm{IC}_{50}$ value followed by leaves (47.96) $\mu \mathrm{g} / \mathrm{ml}$. Hamissou et al., ${ }^{22}$ investigated antioxidant activity of bitter gourd and found to be $82.05^{\mathrm{a}} \pm 7.52 \%$ EAA. Chizoba et al., ${ }^{23}$ researched that antioxidant potential of $\mathrm{M}$. charantia in various meadia. In DPPH method Ic $_{50}$ value was $57,31,73,16,90.52,98.57$ and $83.80 \mu \mathrm{g} / \mathrm{ml}$ for different extract. Yadav et al. ${ }^{24}$ studied the antioxidant activity of methanolic (ME), ethanolic (EE) and butanolic extract (BE) and found to be in ME (0.02), EE (0.03) and BE (0.03) $\mathrm{mg} / \mathrm{ml}$.

\section{ABTS Scavenging Activity}

Principle is based on decolourization in antioxidants present in plant for free radicals 25 .
ABTS + Ammorium/Potassium persulphate -ABTS (blue green).

During in reaction, blue green ABTS cation is changed in back into colourless form 26 . The decolouration, the sample indicates that ABTS cation was condensed by antioxidants in sample and ABTS is measured by spectrophotometricaly at $734 \mathrm{~nm}$ in lipophilic and hydrophilic medium. All samples ABTS activity is carried out and takes ascorbic acid as a standard.

Results of ABTS scavenging were given in table 3 and statistical formula of data is shown in graph-7 Graph-6 shows the curve of ascorbic acid.

IC50 value of ascorbic acid was calculated to be $59.54 \mu \mathrm{g} / \mathrm{ml}$. M. charantia plant shown good ABTS activity in terms of IC50 value. Highest ABTS activity was shown by M.charantia leaves $(\mathrm{IC50}=41.90 \mu \mathrm{g} / \mathrm{ml}$ ) followed by Fruit $(28.14 \mu \mathrm{g} / \mathrm{ml})$.

Lee et al., 17, reported the ABTS of bitter melon fruit at different maturation state ABTS free radical scavenging activity of bitter melon are $46.99 \mathrm{mg} \mathrm{AAE} / 100 \mathrm{~g}$ at 5 days after fertilization their activities significantly increased to $122.87 \mathrm{mg}$ $\mathrm{AAE} / 100 \mathrm{~g}$ at 35 days after fertilization.

Tan et al., 15, calculated ABTS of bitter melon in two different extract and found to be aqueous extract $(94.8 \pm 1.3 \mathrm{a})$ and $80 \%$ ethanol extract $(95.7 \pm 3.5 \mathrm{a})$.

\section{Alpha-Glucosidase Inhibition Activity}

Glycosidases is main class of enzymes which is widely presents in plants and animals. Among these glycosidases, alpha glucosidase catalyze cleavage of bonds involving glucose linked linkage an anomeric center. 
Glycosidases are involved in number of principle biological processes for example digestion, catabolism of glycoproteins and catabolism in glucocenjugates, which are related to many metabolic disorders for example diabetes, obesity, storage disease, HIV and tumors ${ }^{27}$

Alpha glucosidase acting a role of exchange carbohydrate to glucose, hence by inhibiting it, sugar levels in blood can return to its normal extent ${ }^{196}$. Since enzymes is most main biochemical pathways, are considered as potential target in different areas of disease for treatment. Tight regulation of carbohydrate digestion and monosaccharide absorption, might be effective in diabetes, obesity, hypearlipoproteinaemia, and hypearlipidaemia, In this regard, glucosidase inhibitors are of particular importance ${ }^{\mathbf{2 8}}$.

These inhibitors are not supposed to hypoglycemic agents technically, because they do not work direct effect in insulin secretion. Digestion of starch is slower down in intestine by their action, for starchy enters the blood stream, and can by coordinate more successfully by insulin response ${ }^{29}$.

Some $\alpha$-glucosidase inhibitors isolated the plants to perform as alternative drugs and lesser effects, than existing drugs ${ }^{30}$. Carbohydrate assimilation to plant based $\alpha$ glucosidase for therapeutic approach for managing of diabetes-II ${ }^{\mathbf{3 1}}$. Results of alpha glucosidase activity are given table-4. Graph8 shows curve of acarbose. Graph-9 presents the statistical analysis of data. In the present study, we observed that M.charantia fruit give inhibition but M.charantia leaves could not exhibit $\alpha$-glucosidase inhibition.

\section{References}

1. Joseph B. and Jini D, (2013), "Antidibetic effects of $M$. charantia (bitter melon) and its medicinal potency", 'Asian Pacific Journal of Tropical Diseases', Vol.3(2): 93-102.

2. Sharma R., Dwivedi N., Patel G., Pandey P. and Tripathi I.P., (2019), "Phytochemical analysis of Some selected vegetable of Chitrakoot Region", 'Paripex- Indian Journal Of Research', Vol. 8(5): 1-6.

3. Saeed F., Afzaal M., Niaz B., Arshad M.U., Tufail T., Bilal M. and Javed A., (2018), "Bitter melon (Momoradica charantia): A natural healthy vegetable", 'International journal of food properties', Vol 21(1): 1270-1279.

4. Chandra R., Samadder A. and Banerjee J. (2019), "Anti-diabetic activity of Momoradica charantia or Bitter Melon: A review", 'Acta Scientific Pharmaceautical Sciences', Vol. 3(5): 2430.

5. Leelaprakash G., Rose C.J., Gowtham BM., Jauvaji P.K. and Shivram Prasad A., (2011), "Invitro Antimicrobial and Antioxidant activity of Momoradica Leaves", 'Pharmacophore', Vol. 2(4): 244-252.

6. Parmar K., Patel S., Patel B. And patel M.B., (2011), "Effects of bitter ground (Momoradica charantia) fruit juice on glucose tolerance and lipid profile in type-II diabetic rats", 'International journal of drugs development and research' Vol. 3(2): 139-146.

7. Joseph B. And Jini D., (2013), "Antidiabetic effects of Momoradica charantia (bitter melon) and its medicinal potency", 'Asian pacific journal of tropical diseases', Vol. 3(2): 93-102.

8. Tiwari P., Kumar B., Kour M., Kour G. and Kour H., (2011), "Phytochemical screening and extraction: A Review", 'International pharmaceutical Sciencia', Vol. 1(1): 98-106.

9. Tripathi I.P., Mishra M.K., Mishra C., Tripathi R., Kamal A., Tripathi P., Shukla 
V.P., Gangele R. And Pandeya K.B., (2013), "Assessment of Antioxidant and Total Polyphenolic Content of Some Plants of Euphorbiaceae Family”, 'Indian journal of applied research' Vol. 3(10): $1-4$.

10. Asokan A., Thangavel M. and Nisha P. (2015), "In vitro antioxidant activity of Saraca indica methanolic bark extract", Int.J.Curr.Microbiol.App.Sci, Vol. 4(3): 515-520.

11. Tripath I.P., Mishra M. K., Tripathi R., Mishra C., Kamal A.,Shastri L., Dwivedi A., Shukla U. K. and Pandeya K. B., (2014), "Synthesis Spectral, Electrochemical analysis and Screening for Glucosidase inhibition of some complexes of Cobalt (II) and Ethylenediamine", 'Research Journal of Chemical Sciences', Vol. 4(6): 13-17

12. Gomathi S., Vijayabaskaram M., Vaijayanthimala P., Sundaram R.S., Swamy S.S. and Sambathkumr R., (2016), "Phytochemical characterization of Cucumis sativus Linn leaves", 'European journal of pharmaceutical', Vol. 3(4): 378-381.

13. Oeho-Anin Atehibri A.L., Kouakou T.H., Brouk D., Kouadio Y.J. and Gnakri D., (2010), "Evaluation of bioactive components in seeds of Phaseolus vulgaris L. (Fabaceae) cultivated in coled'/voire', 'Journal of applied biosciences', : 1928-1934.

14. Horax R., Hettiarachchy N.S. and Islam S., (2005), "Total phenolic contents and phenolic acid constituents in 4 varieties of Bitter molons (Momoradica charanta) and antioxidant activities of their extract", 'Journal of food science', Vol. 70(4): 275-280.

15. Tan S.P., Stathopoulos C., Parks S. And Roach P., (2014), "An optimised aqueous extract of phenolic compounds from bitter melon with high antioxidant capacity", 'Antioxidants', Vol. 3: 814-829.
16. Chahar S. And Sharma J., (2017) "Phytochemical screening, total flavonoid and phenolic content assays and antioxidant activity of Momoradica charantia L. leaves", 'Asian journal of pharmaceutical education and research', Vol. 6(3): 60-69.

17. Lee S.H., Jeong Y.S., Song J., Hwang KA., Noh G.M. and Hwang I.G., (2017), "Phenolic acid, carotenoid composition and antioxidant activity of bitter melon (Momoradica charantia L.) at different maturation stages", 'International journal of food properties', Vol. 20(53): 47164720.

18. Patel S., Patel T., Parmar K., Patel B. And Patel P., (2011), "Evaluation of antioxidant activity, phenol and flavonoid content of Momoradica charantia Linn. fruit", 'Advance research in pharmaceuticals and biologicals', Vol. 1(2): 120-129.

19. Garba I., Umar A.I., Abdulrahman A.B., Tijjani M.B., Aliyu M.S., Zango U.U and Muhammad A., (2013), "Phytochemical and antibacterial Properties of Garlic extract", 'Bayero journal of pure and applied sciences', Vol. 6(2): 45-48.

20. Khorshed Alam A. And Sultana Khatum C., (2016), "Phytochemical analysis and antioxidant, analgesic and thrombolytic activity investigation of methanol extract of Pisum sativum seed", 'Journal of pharmacognosy and phytochemistry', Vol. 5(6): 366-370.

21. Hasan S.M.R., Hossain Md. M., Akter R., Jamela M., Mazumder Md. E.H. and Rehman S., (2009), "DPPH free radical scavenging activity of some Bangladeshi medicinal plants", 'Journal of medicinal plant research', Vol. 3(11): 875-879.

22. Hamissou M., Smith A.C., Robert E., Jimmy K. And Tripleet II., (2013), "Antioxidant properties of bitter gourd (Momoradica charantia) and Zucchini (Cucurbita pepo)", 'Emir. J.food Agri.', 
Vol. 25(9): 641-647.

23. Chizoba Ekezie F.G., Suneetha J.W., Maheswari U.K., Prasad T.N.V.K.V. and Kumari A.B., (2015), "Analysis of antioxidant potential of Momoradica charantia (Bitter gourd) in-vitro", 'International journal of resent advances in multidisciplinary research', Vol. 2(11): 0989-0992.

24. Yadav B.S., Yadav R., Yadav R.B. and Garg M., (2016), "Antioxidant activity of various extracts of selected gourd vegetables', 'J. Food sci. Technol', Vol. 53(4): 1823-1833.

25. Anjali S.P. and Chauhan G.N., (2015), "Stuudy of antioxidant and antimicrobial activity of medicinal plants utilized in cancer treatment", 'Research journal of recent Sciences', Vol. 4: 15-21.

26. Zurowska D.M. and Wenta W., (2012), "A comparison of ABTS and DPPH methods for assaying the total antioxidant capacity of human milk", 'Acta Sci. Pol., Technol. Aliment.', Vol. 11(1): 83-89.

27. Sancheti S., Sancheti S., Lee S-H, Lee JE. And Seo S-Y., (2011), "Screening of Korean medicinal plant extracts for $\alpha$ glucosidase inhibitory activity", 'Iranian journal of pharmaceutical research', Vol. 10(2) : 261-264.
18. Alagesan K., Thennarasu P, Kumar V., Sankarnarayanan S. and Balsamy T., (2012), "Identification of $\alpha$-glucosidase inhibitors from Psidium guajava leaves and Syzygium cumini Linn. Seeds", 'International Journal of pharma science and research' Vol. 3 (2): 316-322.

19. Mohammed S.A., Yaqub A.G., Sanda K.A., Nicholas A.O., Arastus W., Muhammad M. and Abdullah S., (2013), "Review on diabetes, synthetic drugs and glycemic effects of medicinal plants", 'Journal of medicinal plant research', Vol. 7(36): 2628-2637.

20. Kazeem M.I., Ogunbiyi J.V. and Asnafa A.OT., (2013), "In vitro studies on the inhibition of alpha amylase and alpha glusidase by leafextracts of Picralima nitida (Staph)", 'Tropical journal of pharmaceutical research', Vol. 12(5): 719-725.

21. Reddy N.V.L.S., Anarthe S.J. and Raghavendra N.M., (2010), "In vitro antioxidant and antidiabetic activity of Asystasia gangetica (Chinese violet) Linn. (Acanthaceae)", 'International journal of research in pharmaceutical and biomedical sciences', Vol. 1(2): 7275 .

\section{How to cite this article:}

Ruchika Sharma, Namrata Dwivedi and Indra Prasad Tripathi. 2020. Assessment of Antioxidant and Quantitative Estimation of Momordica charantia (Leaves and Fruit) Plant of Cucurbitaceae Family. Int.J.Curr.Microbiol.App.Sci. 9(10): 3653-3665.

doi: https://doi.org/10.20546/ijcmas.2020.910.423 